\title{
IMPACT ASSESSMENT OF FACTORS INFLUENCING USER'S CONTINUANCE INTENTION TO USE NEAR FIELD COMMUNICATION (NFC)
}

\author{
Dr. Bhumiphat Gilitwala, \\ Director, MBA (Special Track), Graduate School of Business (GSB), \\ Assumption University, Bangkok, Thailand. \\ Dr. Amit Kumar Nag, \\ Associate Professor, Department of Commerce, \\ The Bhopal School of Social Sciences (BSSS), Bhopal, India.
}

\begin{abstract}
Purpose- This research paper intends to determine the factors that influence continuance intention to use NFC for digital mobile payment. The six factors considered in this research are confirmation, perceived usefulness, trust, satisfaction, perceived risk and continuance intention.

Design/Methodology/Approach- The data was collected through online questionnaires filled by 410 Chinese respondents. The data was collected by using convenience sampling and snowball sampling. The validity and reliability of each variable were then examined by Confirmatory Factor Analysis (CFA) in order to estimate the measurement model, for this purpose convergent and discriminant validation was done, followed by testing of structural model framework and testing of research hypotheses.
\end{abstract}

Findings-The results of the present research indicated that all the independent variables have a significant relationship with continuance intention to use NFC for digital mobile payment except perceived risk. Trust indirectly impacted continuance intention significantly.

Practical Implication- The results and findings of the study suggests that companies providing products for NFC mobile payment or service providers can improve trust in order to improve user's continuance intention to adopt and use NFC for mobile payment.

Originality Value- This research helps to develop an insight about the most important factors Influencing User's Continuance Intention to Use Near Field Communication (NFC) for Digital Mobile Payment.

Keywords: continuance intention, confirmation, perceived usefulness, satisfaction, perceived risk, trust, NFC, mobile payment.

\section{INTRODUCTION}

Present days mobile phones are more like portable computers, equipped with varied, useful functions besides performing the basic function of communicating with others. The recent innovations in telecommunication industry have further boosted the usefulness of mobile phones across the globe. These days mobile phones are also used for making financial payments which are also popularly known as mobile payments and is one of the most appreciated and widely used functions of mobile phones. Mobile payment (MP) is actually a payment method that uses mobile devices to initiate and confirm a particular financial transaction. There are numerous factors that have resulted in the surge of digital mobile payment over the years, one amongst them is that most of the smart phone suppliers are now providing mobile wallets and near field communication (NFC) function to support digital mobile payment. Moreover, with increasing acceptance of ride-sharing and other services use of mobile payment got further boosted.

While considering various parameters such as transaction volume, mobile payment penetration rate or mobile payment user's scale, China is considered as a world leader. China reported that a total of 60.531 billion mobile payment services was processed by various banking financial institutions in 2018, with a transaction value of RMB 277.39 trillion, 
showing an increase of $61.19 \%$ and $36.69 \%$ respectively as compared to the year 2017 in terms of transaction volume (conferring to the declaration made by the People's Bank of China Payment and Settlement Department in 2018). Reports highlighted that the mobile payment penetration rate in the second quarter of 2018 was as high as $92.4 \%$ amongst mobile phone users in China and almost about 890 million people were using mobile payment by the end of the first half of 2018. China Internet Network Information Center informed that mobile payment user's scale reached almost around $73.4 \%$ of total mobile phone users by the end of July 2019, reaching 37.88 million as compared to 2018 .

In recent time it is evident that despite of convenience in payment using the NFC, majority of the users prefer $\mathrm{QR}$ code payment in place of NFC mobile payment, though payment industry adopted NFC technology prior to QR code. Putting a question mark that convenience is not the only factor that affects the user's decision on payment method, there are many other factors that impact user's decision. Thus, an attempt has been made in the research work to assess various factors that affect intention to use NFC for mobile payment.

\section{LITERATURE REVIEW}

Expectation Disconfirmation Theory (EDT), or expectation confirmation model (ECM) is an elementary model in the marketing literature and consumer behavior, explaining consumers' satisfaction and post-consumption behavior (Churchill \& Surprenant, 1982); (Oliver, 1980). Users' satisfaction is majorly influenced by the degree of disconfirmation towards a payment (Oliver, 1980). The more users are satisfied, the more is the possibility that the user is likely to continue usage. On the other hand, the more dissatisfaction the consumers perceived, the more is the possibility that users will start avoiding reuse of the same products or services again in the future (Susanto, Chang, \& Ha, 2015).

Confirmation mentions the degree to which pre usage expectation of any technology confirms in terms of post-adoption performance satisfaction of the same technology. Bhattacherjee (2001) explained, in case of mismatch between pre-expected perceptions and post-usage experience, cognitive dissonance and dissatisfaction crops up and then, users alter their acuities to minimize this dissonance. Higher customer satisfaction and loyalty are reflected when the perceived performance is equal to or greater than expected performance (Patterson, Johnson, \& Spreng, 1997).

Perceived usefulness is "the degree to which a person believes that using a particular system would enhance his or her job performance" (Davis, 1989). Benefits such as more accuracy, efficiency, and quickness in job completion can be ensured by using an effective information system (Yang, Motohashi, \& Chen, 2009). (Weng, Zailani, Iranmanesh, \& Hyun, 2017) in their research established a direct association between perceived usefulness and user satisfaction, perceived usefulness and continuance usage intention.

Satisfaction refers to the pleasure or feelings of the users that are formed through mutual interactions with service providers or merchants (Oliver, 1980). Satisfaction plays an important role in building and retaining loyalty (Chuah, Rauschnabel, Marimuthu, Thurasamy, \& Nguyen, 2017). Satisfaction also plays a predominant role in information system where an increase in user's satisfaction, strengthen users' intention towards continuous usage (Veeramootoo, Nunkoo, \& Dwivedi, 2018). Liao et al. (2009) in their research conducted in Taiwan established a significant positive relationship between perceived usefulness and user satisfaction as well as between perceived usefulness and the continuance usage intention.

Trust is the belief of reliability and is also considered to be a common antecedent in study of satisfaction and loyalty (Schaupp \& Bélanger, 2005). (Chen \& He, 2003) emphasized the importance of trust in online business, where there is low or even zero interaction.

Perceived risk was defined as "a consumer's perception about the uncertainty and the adverse consequences of a transaction performed by a seller". (Yuan, Liu, \& Yao, 2016) established strongest total effect between satisfaction and perceived risk (0.237 and 0.323 , respectively). They also highlighted that the impact of perceived risk was stronger in men. (Shiva, Narula, \& Shahi, 2020) in their 
study indicated that "there is a tendency to exhibit overtrading by retail investors in the state of fear of no investment information and lack of convenience due to news in smartphones".

Continuance intention refers to the repeated usage of a product or a service. It reflects users' inclination to consume or use a particular product (Bhattacharjee, 2001). The critical relationship between confirmation and user satisfaction supports the concept of continuous intention (Veeramootoo, Nunkoo, \& Dwivedi, 2018).

\section{CONCEPTUAL FRAMEWORK}

Based on the literatures from "Drivers of continuance intention with mobile banking apps" (Chayawan, Peter, Kannika, \& Simon, 2019), and "The continuance usage intention of Alipay Integrating context-awareness and technology continuance theory (TCT)" (Abul $\&$ Bao, 2019), the conceptual framework was structured.
$\mathrm{H}_{2} \mathrm{~A}_{0}$ : Confirmation has an influence on user's satisfaction on using NFC for mobile payment. $\mathrm{H}_{2} \mathrm{~B}_{0}$ : Perceived usefulness has an influence on user's satisfaction using NFC for mobile payment.

$\mathrm{H}_{2} \mathrm{C}_{0}$ : Trust has an influence on user's satisfaction using NFC for mobile payment.

$\mathrm{H} 3 \mathrm{~A}_{0}$ : User's satisfaction has an influence on continuance intention of NFC for mobile payment.

$\mathrm{H}_{3} \mathrm{~B}_{0}$ : Perceived risk has an influence on continuance intention of NFC for mobile payment.

\section{RESEARCH METHODOLOGY}

The researcher used self-administered online questionnaire. The questions were derived from the previous studies and were modified to fit this research. The Chinese who had used NFC mobile payment were considered as a target population of this study. The research applied non-probability sampling technique, including convenient sampling and snowball sampling. Cronbach's Alpha test was applied

Figure 1 Conceptual framework

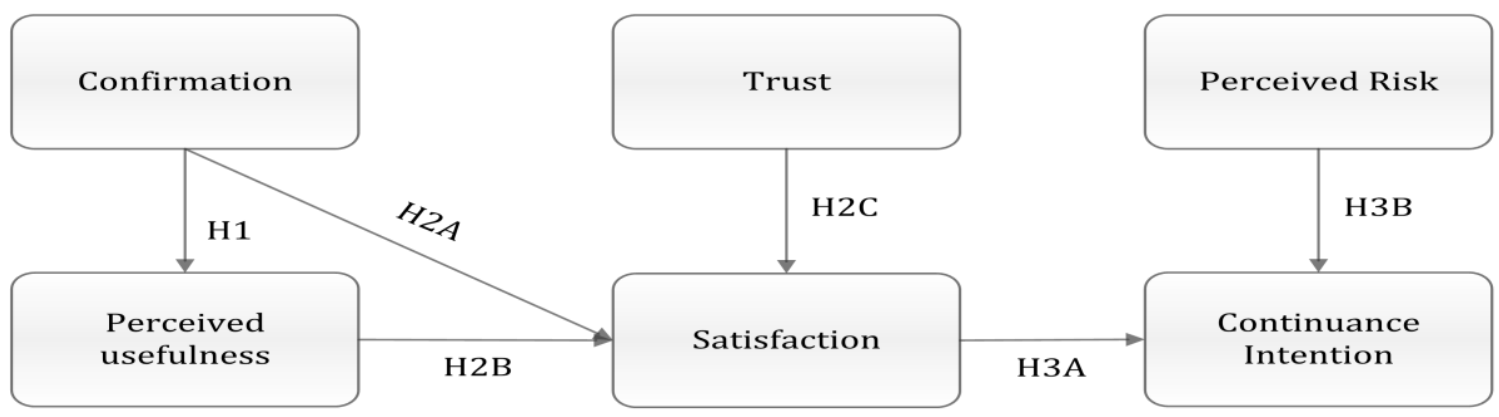

\section{RESEARCH HYPOTHESIS}

Following are the hypotheses for the present research work:

$\mathrm{H} 1_{0}$ : Confirmation has an influence on perceived usefulness of NFC for mobile payment. to test the reliability of the questionnaire with a sample of 40 respondents. The sample size considered for the present research was 410 respondents. The validity and reliability of each variable were then examined by Confirmatory Factor Analysis (CFA) in order to estimate the measurement model, for this

Table 1: Summary of Cronbach's Alpha Coefficient for Pretest

\begin{tabular}{|l|c|c|c|}
\hline Variables & Cronbach's Alpha & Number of Items & Result \\
\hline Confirmation & 0.942 & 3 & Pass \\
\hline Perceived Usefulness & 0.916 & 4 & Pass \\
\hline Satisfaction & 0.937 & 3 & Pass \\
\hline Trust & 0.956 & 4 & Pass \\
\hline Perceived Risk & 0.773 & 3 & Pass \\
\hline Continuance Intention & 0.889 & 3 & Pass
\end{tabular}


purpose convergent and discriminant validation was done.

\section{The Results of Reliability}

Cronbach's Alpha Coefficient test was conducted as a pretest on a sample of 40 respondents using the acceptance criteria of a $=0.6$ in order to confirm suitability and consistency of the research instrument (Peterson, 1994). Cronbach's Alpha Coefficient test results as shown in table 1, indicates that all seven variables were found to be reliable and acceptable $(\alpha>0.6)$ for this study. The results showed the value of Cronbach's Alpha for confirmation (0.942), perceived usefulness (0.916), satisfaction (0.937), trust (0.956), perceived risk (0.773) and continuance intention (0.889) confirming ( $\alpha>0.6)$.

\section{DISCUSSION AND CONCLUSION}

Table 2: Summary Analysis of the Demographic Features Using Frequency, Percentage and Cumulative Percentage

\begin{tabular}{|c|c|c|c|}
\hline $\begin{array}{c}\text { Demographic } \\
\text { Factors }\end{array}$ & Frequency & Percent & $\begin{array}{c}\text { Cumulative } \\
\text { Percent }\end{array}$ \\
\hline Gender & & & \\
\hline Male & 252 & 61.46 & 61.46 \\
\hline Female & 158 & 38.54 & 100 \\
\hline Total & $\mathbf{4 1 0}$ & $\mathbf{1 0 0}$ & \\
\hline Age & 11 & 2.68 & 2.68 \\
\hline Under 19 & 169 & 41.22 & 43.9 \\
\hline $19-29$ & 177 & 43.17 & 87.07 \\
\hline $30-39$ & 43 & 10.49 & 97.56 \\
\hline $40-49$ & 10 & 2.44 & 100 \\
\hline Over 50 & $\mathbf{4 1 0}$ & $\mathbf{1 0 0}$ & \\
\hline Total & & & \\
\hline Educational Level & 82 & 20.00 & 20.00 \\
\hline $\begin{array}{c}\text { High school or } \\
\text { less }\end{array}$ & 254 & 61.95 & 81.95 \\
\hline Bachelor degree & 67 & 16.34 & 98.29 \\
\hline Master degree & 7 & 1.71 & 100 \\
\hline PhD or above & $\mathbf{4 1 0}$ & $\mathbf{1 0 0}$ & \\
\hline Total & & & \\
\hline
\end{tabular}

The researchers administered responses from 410 respondents out of which there were 254 male respondents representing $61.95 \%$ of the sample size. While remaining 158 were female respondents representing $38.54 \%$ of the sample size. The majority of the respondents falls in the age bracket of 30 to 39 years, with 177 persons representing $43.17 \%$. Followed by 169 persons in the age bracket of 19 to 29 years, representing $41.22 \%$ of the total respondents and only 10 persons were from age more than 50 years, representing only $2.44 \%$ of the total respondent. Most of the respondents were having a bachelor degree with the number of 254 representing $61.95 \%$ of the total respondents. The smallest group comprises of a doctoral degree or above, with 7 persons representing $1.71 \%$.

\section{Confirmatory Factor Analysis}

The proposed measurement model was assessed by using confirmatory factor analysis for all the constructs. Confirmatory factor analysis was applied to test the consistency of all the construct as well as to check whether the data fits the hypothesized measurement model or not.

Table 3: Results of Confirmatory Factor Analysis, Average Variance Extracted and Construct Reliability

\begin{tabular}{|c|c|c|c|c|c|}
\hline Variables & $\begin{array}{c}\text { Factor } \\
\text { Loading }\end{array}$ & S.E. & $\begin{array}{c}\text { Critical } \\
\text { Ratio }\end{array}$ & $\begin{array}{l}\text { Average } \\
\text { Variance } \\
\text { Extracted }\end{array}$ & $\begin{array}{l}\text { Construct } \\
\text { Validated }\end{array}$ \\
\hline Confirmation & & & & 0.838 & 0.939 \\
\hline CON1 & 0.900 & & & & \\
\hline CON2 & 0.921 & 0.034 & 29.766 & & \\
\hline CON3 & 0.927 & 0.033 & 30.447 & & \\
\hline \begin{tabular}{|l|} 
Perceived \\
Usefulness
\end{tabular} & & & & 0.869 & 0.964 \\
\hline PU1 & 0.929 & & & & \\
\hline PU2 & 0.935 & 0.027 & 35.660 & & \\
\hline PU3 & 0.935 & 0.028 & 35.721 & & \\
\hline PU4 & 0.932 & 0.027 & 35.144 & & \\
\hline Satisfaction & & & & 0.870 & 0.953 \\
\hline SAT1 & 0.935 & & & & \\
\hline SAT2 & 0.924 & 0.028 & 34.463 & & \\
\hline SAT3 & 0.948 & 0.027 & 37.931 & & \\
\hline Trust & & & & 0.865 & 0.962 \\
\hline TRU1 & 0.922 & & & & \\
\hline TRU2 & 0.913 & 0.030 & 32.419 & & \\
\hline TRU3 & 0.942 & 0.029 & 35.923 & & \\
\hline TRU4 & 0.943 & 0.027 & 36.309 & & \\
\hline $\begin{array}{l}\text { Perceived } \\
\text { Risk } \\
\end{array}$ & & & & 0.886 & 0.959 \\
\hline PR1 & 0.921 & & & & \\
\hline PR2 & 0.951 & 0.028 & 36.103 & & \\
\hline PR3 & 0.952 & 0.027 & 36.274 & & \\
\hline $\begin{array}{l}\text { Continuance } \\
\text { Intention }\end{array}$ & & & & 0.881 & 0.957 \\
\hline CI1 & 0.918 & & & & \\
\hline CI2 & 0.951 & 0.030 & 31.84 & & \\
\hline $\mathrm{CI} 3$ & 0.946 & 0.031 & 30.879 & & \\
\hline
\end{tabular}

Source: Author's own work.

Notes: ${ }^{* * *}=$ significant at the 0.001 significant level $(\mathrm{p}<0.001)$

The results of the confirmatory factor analysis, average variance extracted and construct reliability indicates that all the constructs are consistent and fits the measurement model. The results of the factor loadings are more than the minimum required threshold of 0.70 . On analyzing average variance extracted, it is 
evident from the table 3 that the AVE of each construct exceeded the minimum required threshold of 0.50 establishing relationship between variance captured by a construct to variance due to measurement error. Construct reliability was also established as results in table 3 also exceeded the minimum required threshold of 0.70 indicating that all constructs are theoretically related to each other.

\section{Discriminant Validity}

Notes: Figures in bold represent Square Root of Average Variance Extracted (AVE) and signifies discriminant validity. Other figures are correlation coefficients.
Table 5: Goodness of Fit Indices of the Structural Model

\begin{tabular}{|l|c|c|}
\hline \multicolumn{1}{|c|}{ Index } & Criteria & Result of this Study \\
\hline CMIN/df & $<3.00$ & 2.733 \\
\hline GFI & $>0.90$ & 0.908 \\
\hline CFI & $>0.90$ & 0.976 \\
\hline IFI & $>0.90$ & 0.976 \\
\hline NFI & $>0.90$ & 0.963 \\
\hline TLI & $>0.90$ & 0.972 \\
\hline RMSEA & $<0.08$ & 0.065 \\
\hline
\end{tabular}

Table 5 shows that the CMIN/df was 2.733, indicating a good fit. Other indices of goodness of fit such as, GFI (Goodness of Fit)

Table 4: Discriminant Validity

\begin{tabular}{|c|c|c|c|c|c|c|}
\hline Constructs & Confirmation & $\begin{array}{c}\text { Perceived } \\
\text { Usefulness }\end{array}$ & Satisfaction & Trust & $\begin{array}{c}\text { Perceived } \\
\text { Risk }\end{array}$ & $\begin{array}{c}\text { Continuance } \\
\text { Intention }\end{array}$ \\
\hline Confirmation & $\mathbf{0 . 9 1 5}$ & & & & & \\
\hline Perceived Usefulness & 0.860 & $\mathbf{0 . 9 3 2}$ & & & & \\
\hline Satisfaction & 0.865 & 0.898 & $\mathbf{0 . 9 3 3}$ & & & \\
\hline Trust & 0.808 & 0.816 & 0.926 & $\mathbf{0 . 9 3 0}$ & & \\
\hline Perceived Risk & 0.352 & 0.389 & 0.360 & 0.348 & $\mathbf{0 . 9 4 1}$ & \\
\hline Continuance Intention & 0.781 & 0.758 & 0.850 & 0.855 & 0.374 & $\mathbf{0 . 9 3 9}$ \\
\hline
\end{tabular}

Source: Author's own work.

Results of table 4 show that all crossed constructs correlation values are lesser than the square root of the average variance extracted (AVE), indicating the establishment of discriminant validity. Thus, measurement constructs intended to be unrelated were found unrelated.

\section{Analysis of the Structural Model}

Structural equation modeling was employed in order to test the hypotheses and the results are shown in table 5 and 6 .

\section{Figure 2: Results of Structural Model}

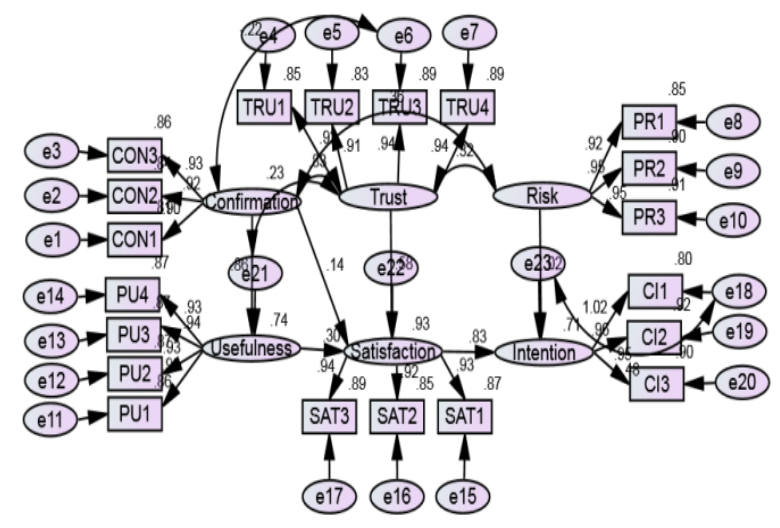

is 0.908 , CFI (Comparative Fit Index) is 0.976, IFI (Incremental Fit Index) is 0.976, NFI (Normed Fit Index) is 0.963 and TLI (TruckerLewis Index) is 0.972. Each indices are greater than minimum threshold of 0.90. The RMSEA (Root Mean Square Error of Approximation) is 0.065 , which is also lower than 0.08 as required, indicating that the model is a good fit.

Total effect of different constructs on dependent variable (continuance intention) was determined by the total of direct and indirect effect of various independent variables such as confirmation, perceived usefulness, trust, satisfaction and perceived risk. The significant direct effect of confirmation on perceived usefulness was 0.862 . Trust has the highest direct effect on satisfaction $(\beta=0.578)$, followed by perceived usefulness $(\beta=0.295)$ and confirmation $(\beta=$ $0.141)$. Results of table no.7 also showed that satisfaction has highest direct influence on continuance intention $(\beta=0.832)$. On the other hand, independent variables such as trust, perceived usefulness and confirmation indirectly influences dependent variable (continuance intention) with the help of satisfaction (mediating variable). Of the three 
independent variables (trust, perceived usefulness and confirmation), trust has the highest indirect influence $(\beta=0.481)$ on continuance intention, followed by confirmation $(\beta=0.330)$ and perceived usefulness $(\beta=0.246)$. Thus, satisfaction fully mediates the association among trust, perceived usefulness, confirmation and continuance intention.

\section{CONCLUSION}

users to continue to use NFC mobile payment. When they develop more trust on NFC mobile payment then they will be more interested to use NFC mobile payment.

The most significant factor impacting continuance intention to use is satisfaction. The more satisfied the users are, the more is the possibility of continuance intention to use NFC mobile payment again. Factors such as

Table 6: Hypotheses Testing Results of the Structural Model

\begin{tabular}{|c|c|c|c|c|}
\hline Hypotheses & $\begin{array}{l}\text { Standardized } \\
\text { Regression } \\
\text { Weight }\end{array}$ & t-value & p-value & Supported \\
\hline $\mathrm{H} 1_{0}$ : Confirmation $=>$ Perceived Usefulness & 0.862 & 22.460 & *** & Yes \\
\hline $\mathrm{H}_{2} \mathrm{~A}_{0}$ : Confirmation $=>$ Satisfaction & 0.141 & 3.156 & .002 & Yes (at 0.01) \\
\hline $\mathrm{H}_{2} \mathrm{~B}_{0}$ : Perceived Usefulness $=>$ Satisfaction & 0.295 & 6.715 & $* * *$ & Yes \\
\hline $\mathrm{H}_{2} \mathrm{C}_{0}$ : Trust $=>$ Satisfaction & 0.578 & 14.117 & $* * *$ & Yes \\
\hline $\begin{array}{l}\mathrm{H}_{3} \mathrm{~A}_{0}: \text { Satisfaction } \quad=>\text { Continuance } \\
\text { Intention }\end{array}$ & 0.832 & 26.285 & $* * *$ & Yes \\
\hline $\begin{array}{l}\mathrm{H}_{3} \mathrm{~B}_{0}: \text { Perceived Risk }=>\text { Continuance Usage } \\
\text { Intention }\end{array}$ & 0.023 & 0.845 & 0.398 & No \\
\hline
\end{tabular}

Source: Author's own work.

Note: ${ }^{* * *} \mathrm{p}<0.001$

Table 7: Standardized Direct, Indirect and Total Effects of Various Constructs

\begin{tabular}{|c|c|c|c|c|c|c|}
\hline \multirow{2}{*}{\multicolumn{2}{|c|}{ Dependent Variables $\downarrow$}} & \multicolumn{5}{|c|}{ Independent Variables $\downarrow$} \\
\hline & & \multirow{2}{*}{$\begin{array}{c}\text { Confirmation } \\
0.862 \\
\end{array}$} & \multirow{2}{*}{\begin{tabular}{|c|} 
Perceived \\
Usefulness \\
-
\end{tabular}} & \multirow{2}{*}{$\begin{array}{c}\text { Trust } \\
-\end{array}$} & \multirow{2}{*}{$\begin{array}{c}\text { Satisfaction } \\
-\end{array}$} & \multirow{2}{*}{$\begin{array}{c}\begin{array}{c}\text { Perceived } \\
\text { Risk }\end{array} \\
- \\
\end{array}$} \\
\hline \multirow{3}{*}{$\begin{array}{l}\text { Perceived } \\
\text { Usefulness }\end{array}$} & $\mathrm{DE}$ & & & & & \\
\hline & IE & - & - & - & - & - \\
\hline & $\mathrm{TE}$ & 0.862 & - & - & - & - \\
\hline \multirow{3}{*}{ Satisfaction } & $\overline{\mathrm{DE}}$ & 0.141 & 0.295 & 0.578 & - & - \\
\hline & IE & 0.255 & - & - & - & - \\
\hline & $\mathrm{TE}$ & 0.396 & 0.295 & 0.578 & - & - \\
\hline \multirow{3}{*}{$\begin{array}{l}\text { Continuance } \\
\text { Intention }\end{array}$} & $\overline{\mathrm{DE}}$ & - & - & - & 0.832 & 0.023 \\
\hline & IE & 0.330 & 0.246 & 0.481 & - & - \\
\hline & $\mathrm{TE}$ & 0.330 & 0.246 & 0.481 & 0.832 & 0.023 \\
\hline
\end{tabular}

Source: Author's own work.

Notes: DE: Direct Effects, IE: Indirect Effects and TE: Total Effects

The study highlighted that confirmation, perceived usefulness, and trust had a positive and significant impact on the continuance intention of using NFC for digital mobile payment through user's satisfaction. It also implied that user's satisfaction directly influenced continuance intention to use NFC mobile payment. Moreover, trust can be considered as one of the factors that influences confirmation, perceived usefulness and trust are amongst the numerous factors that have impacted users' satisfaction in using NFC mobile payment, but trust is undoubtedly the most significant factor that has emerged to influence user satisfaction. Followed by the perceived usefulness and confirmation. The result of this research reinforced the findings of previous research (Liao, Palvia, \& Chen, 
2009) that a significant positive relationship exists between the perceived usefulness and user satisfaction, also establishing that confirmation has significant impact on satisfaction. (Veeramootoo, Nunkoo, \& Dwivedi, 2018) in their research established that there is a significant relationship between confirmation and user satisfaction, thus the result of the present research also supports their findings.

The perceived risk has an insignificant impact on users' continuance intention to use NFC mobile payment. Intension to use NFC mobile payment will increase only when the users feel safe about NFC mobile payment. It contradicts to the previous research. In another research (Hyun-Sun, 2017), it showed perceived risk had a negative effect on Fintech continuance intention.

\section{RECOMMENDATIONS}

The results of the research showed that users' trust, perceived usefulness, confirmation, perceived risk, and users' satisfaction with the product or service affected the users' continuance intention to use NFC for digital mobile payment. Among them, users' trust had the highest influence on user's satisfaction on NFC mobile payment. Moreover, user's satisfaction has the highest influence on user's continuance intention toward NFC mobile payment. The following steps are therefore suggested to companies and service providers of the NFC payment so that users' continuance intention of using NFC payment can be improved: Firstly, utmost care needs to be taken to improve users' trust on NFC mobile payment products and services. As it is concluded that, trust has not only directly impacted users' continuance intention to use NFC mobile payment, but also impacted indirectly to users' continuance intention through users' satisfaction. Service providers of NFC mobile payment can improve users' trust only when they keep up to their promises and commitments to users by keeping in mind, the users' interests. The possibilities of more user to continue using NFC mobile payment can persist only when more users develop more trust on NFC mobile payment.

Secondly, service providers should improve users' satisfaction by providing prompt and refined services in order to increase users' continuance intention on usage of NFC mobile payment. Satisfied users of NFC mobile payment products or services will therefore continue to use the same product and services. They will also encourage others to use the same by their word of mouth publicity. On the other hand, if the users of NFC mobile payment feel unsatisfied, they would turn to alternatives, as they have other choices available. This study suggested that users' satisfaction was majorly and positively affected by trust, perceived usefulness and confirmation though there are many other ways to improve the same. Therefore, utmost care needs to be taken by NFC mobile payment companies and service providers to improve users' satisfaction. As explained previously, trust is the most important factor influencing or affecting user's satisfaction, the second important factor is perceived usefulness. Quick and effective NFC mobile payment will encourage the users to use it for their future transactions. Confirmation is the third factor affecting user satisfaction, companies and service providers should make products or services such as to match user's expectations.

\section{LIMITATIONS AND FURTHER STUDY}

Primarily the data of the present research work confine to China, but the result of this research can be applied to other countries too. Chinese prefer to make mobile payment with QR code rather than the NFC during payment as habitual behavior. However, the situation cannot be considered to be the same in another part of the world. In some countries, users are familiar with tap and go payment by using a credit card which is almost the same technology as an NFC mobile payment, indicating the need to have extensive research related to the same in those countries.

The research neglects certain important constructs such as social influence, selfefficacy and so forth, which could possibly explain continuance usage behavior and consider only continuance usage as relevant construct for mobile payment. Suggesting that further research can be conducted using those constructs. Further, cross-country longitudinal data can be used for future researches.

\section{REFERENCES}

Abul, K., \& Bao, Y. (2019). Integrating contextawareness and technology continuance theory (TCT). 
Bhattacherjee, A. (2001). Understanding information systems continuance: an expectation-confirmation model. MIS Quarterly, 25, pp. 351-370.

Chayawan, P., Peter, M. D., Kannika, L., \& Simon, Z. (2019). Drivers of continuance intention with mobile banking apps.

Chen, R., \& He, F. (2003). Examination of brand knowledge, perceived risk and consumers' intention to adopt an online retailer. Total Quality Management and Business Excellence, 14, pp. 677-693.

Chuah, S.-W., Rauschnabel, P., Marimuthu, M., Thurasamy, R., \& Nguyen, B. (2017). Why do satisfied customers defect? A closer look at the simultaneous effects of switching barriers and inducements on customer loyalty. Journal of Service Theory and Practice, 27, pp. 616-641.

Churchill, G., \& Surprenant, C. (1982). An investigation into the determinants of customer satisfaction. Journal of Marketing Research, 19, pp. 491-504.

Davis, F. (1989). erceived usefulness, perceived ease of use, and user acceptance of information technology. MIS Quarterly, 13, pp. 319-340.

Liao, C., Palvia, P., \& Chen, J.-L. (2009). Information technology adoption behavior life cycle: toward a technology continuance theory (TCT). International Journal of Information Management, 29, pp. 309-320.

Oliver, R. (1980). A cognitive model of the antecedents and consequences of satisfaction decisions. Journal of Marketing Research, 17, pp. 460-469.

Patterson, P., Johnson, L., \& Spreng, R. (1997). Modeling the determinants of customer satisfaction for business-to- business professional services. Journal of the Academy of Marketing Science, 25, pp. 4-17.

Schaupp, L., \& Bélanger, F. (2005). A conjoint analysis of online consumer satisfaction. Journal of Electronic Commerce Research, 6, pp. 95-111.

Shiva, Narula, \& Shahi, (2020). What drives retail investors' investment decisions? Evidence from no mobile phone phobia (nomophobia) and investor fear of missing out (I - FOMO). Journal of Content, Community $\mathcal{E}$ Communication, 11, pp.2-20.

Susanto, A., Chang, Y., \& Ha, Y. (2015). Determinants of continuance intention to use the smartphone banking services.

Veeramootoo, N., Nunkoo, R., \& Dwivedi, Y. (2018). What determines success of an e-government service? Validation of an integrative model of e-filing continuance usage. Government Information Quarterly, 35, pp. 161-174.

Weng, G., Zailani, S., Iranmanesh, M., \& Hyun, S. (2017). Mobile taxi booking application service's continuance usage intention by users. Transportation Research Part D: Transport and Environment, 57, pp. 207216.

Yang, C.-H., Motohashi, K., \& Chen, J.-R. (2009). Are new technology-based firms located on science parks really more innovative? Evidence from Taiwan. Research Policy, 38, pp. 77-85.

Yuan, S., Liu, Y., \& Yao, R. (2016). An investigation of users' continuance intention towards mobile banking in China. Information Development, 32, pp. 20-34. 